\title{
EMISI GAS RUMAH KACA DAN HASIL GABAH DARI BEBERAPA VARIETAS PADI UNGGUL TIPE BARU DI LAHAN SAWAH TADAH HUJAN DI JAWA TENGAH
}

\section{GREENHOUSE GASES EMISSION AND GRAIN YIELD FROM SEVERAL SUPERIOR RICE VARIETIES UNDER RAINFED LOWLAND FIELD IN CENTRAL JAVA}

\author{
A. Wihardjaka dan Sarwoto ${ }^{13}$
}

(Diterima tanggal 04-08-2014; Disetujui tanggal 04-12-2014)

\begin{abstract}
ABSTRAK
Pelepasan varietas unggul tipe baru sebagai jawaban akan peningkatan kebutuhan pangan nasional. Beberapa varietas padi telah rentan terhadap serangan organisme pengganggu tanaman, sehingga potensial menurunkan hasil gabah. Di sisi lain, budidaya padi sawah berkontribusi terhadap pelepasan gas rumah kaca terutama metana ke atmosfer yang dapat menyebabkan pemanasan global. Informasi emisi metana dari beberapa varietas inhibrida masih terbatas. Penelitian dilaksanakan dengan tujuan untuk mengetahui besarnya emisi metana dari beberapa varietas inhibrida yang dibudidayakan di lahan sawah tadah hujan. Percobaan disusun menggunakan rancangan acak kelompok dengan tiga ulangan dan perlakuan varietas padi yang meliputi Inpari 14, Inpari 15, Inpari 17, Inpari 18, Inpari 20 , Ciherang, Situ Bagendit, IR64. Inpari 17 dan 18 merupakan kultivar padi yang menghasilkan emisi metana lebih rendah daripada IR64, Ciherang, dan Situ Bagendit. Emisi metana terendah dari kultivar yang diuji adalah Inpari $18<$ Inpari $17<$ IR64 $<$ Situ Bagendit $<$ Ciherang $<$ Inpari $20<$ Inpari $14<$ Inpari 15 . Hasil gabah kering giling tertinggi dari kultivar yang diuji di lahan sawah tadah hujan adalah Inpari $17<$ Inpari $18<$ Situ Bagendit $<$ Inpari $15<$ Inpari $20<$ Inpari $14<$ IR64 < Ciherang. Inpari 17 dan 18 merupakan kultivar padi yang berdaya hasil tinggi dan rendah emisi metana dengan indeks emisi metana masing-masing $0,01 \mathrm{~kg} \mathrm{CH}_{4} \mathrm{~kg}^{-1}$ gabah.
\end{abstract}

Kata kunci: emisi metana, varietas inbrida, sawah tadah hujan, gabah, jawa tengah

\begin{abstract}
The release of a new type of high yielding variety is to respond the increase of national food consumption. Several rice varieties have been vulnerable to major rice pests'attacks that potentially reduce grain yield. On the other hand, rice cultivation contributes to the release of greenhouse gases, especially methane, into the atmosphere that can cause global warming. Information of methane emissions from several non hybrid varieties is still limited. The field experiment was conducted in order to determine the magnitude of methane emissions from several non hybrid varieties cultivated in the rainfed areas. The eight treatments of rice variety were arranged using a randomized block design with three replications. The rice varieties tested were Inpari 14, Inpari 15, Inpari 17, Inpari 18 , Inpari 20 , Ciherang, Situ Bagendit, IR64. Variables observed were methane flux, grain yield, and biomass weight. Inpari 17 and 18 rice cultivars emitted lower methane emission than IR64, Ciherang, Situ Bagendit, and other Inpari varieties tested. Lowest methane emissions from rice varieties tested was Inpari $18<$ Inpari $17<$ IR $64<$ Situ Bagendit $<$ Ciherang $<$ Inpari $20<$ Inpari $14<$ Inpari 15. The highest grain yield of rice varieties tested in rainfed areas was Inpari $17<$ Inpari $18<$ Situ Bagendit $<$ Inpari $15<$ Inpari $20<$ Inpari $14<$ IR64 $<$ Ciherang. Rice variety of Inpari 17 and 18 rice was variety with high yielding and low methane emissions with methane emission index as much as $0.01 \mathrm{~kg} \mathrm{CH}_{4} \mathrm{~kg}^{-1}$ grains, respectively.
\end{abstract}

Keywords: methane emission, non hybrid variety, rainfed lowland rice, grain, central java 


\section{PENDAHULUAN}

Sawah tadah hujan mempunyai andil dalam memenuhi kebutuhan pangan nasional. Sebagai lahan sub-optimal, sawah tadah hujan dihadapkan pada berbagai kendala yang berpengaruh terhadap rendahnya produksi padi tadah hujan, antara lain kesuburan tanah rendah, curah hujan tidak menentu, cekaman kekeringan, dan pertumbuhan gulma yang pesat. Pemenuhan kebutuhan pangan terutama beras dari sawah tadah hujan dapat dicapai dengan penggunaan varietas padi unggul tipe baru untuk menggantikan varietas lama yang rentan terhadap serangan organisme pengganggu tanaman (OPT), antara lain varietas inbrida baru yang telah dilepas pemerintah.

Budidaya padi sawah dipandang sebagai salah satu sumber utama emisi gas rumah kaca di sektor pertanian. Gas metana (CH4) merupakan salah satu gas rumah kaca (GRK) utama yang dilepaskan dari interface tanahtanaman padi sawah, antara lain melalui difusi, ebulisi, media tanaman padi[1]. Besarnya emisi metana yang dilepaskan dalam budidaya padi sawah tergantung pada jenis tanah, kondisi kelengasan tanah, sifat fisikokimia tanah[2], suhu tanah, dan faktor pengelolaan tanaman termasuk varietas yang digunakan[3]. Potensi pemanasan global $\mathrm{CH}_{4}$ adalah 25 kali lebih besar daripada massa setara $\mathrm{CO}_{2} \mathrm{di}$ atmosfer[4]. Metana memberikan sumbangan 14\% dari emisi GRK global akibat tingginya laju difusi $\mathrm{CH}_{4}$ ke dalam tanah dan oksidasi $\mathrm{CH}_{4}$ oleh mikroba metanotropik. Pada sistem sawah tadah hujan, kondisi tanah aerob anaerobik terjadi silih berganti sehingga berpengaruh terhadap dinamika gas $\mathrm{CO}_{2}$ dan $\mathrm{CH}_{4}$ dari tanah.
Tanaman padi berperan penting dalam melepaskan metana ke atmosfer. Lebih dari $80 \%$ metana dilepaskan dari tanah ke atmosfer melalui tanaman padi yang bertindak sebagai cerobong (chimney). Oksigen dipasok dari atmosfer ke perakaran tanaman padi melalui jaringan aerenkhima. Jaringan aerenkhima tanaman padi berfungsi sebagai media respirasi dan pertukaran gas di dalam tanah seperti difusi metana dari tanah tereduksi[5]. Selain itu, pelepasan metana dalam jumlah lebih sedikit dari tanah sawah ke atmosfer dapat berupa gelembung-gelembung pada permukaan air atau berdifusi secara lambat dari tanah melalui air[6]. Perbedaan konsentrasi air antara rhizofer dan ruang intrasel akar menyebabkan difusi metana terlarut dan perubahan gas ke dalam dinding kortek yang didistribusikan ke batang tanaman melalui jaringan aerenkhima. Gas metana dilepaskan ke atmosfer melalui pori-pori mikro tanaman[7].

Pemilihan varietas padi umumnya berdasar atas potensinya terhadap hasil tinggi dan sifatsifat lainnya seperti ketahanannya terhadap hama dan penyakit tanaman tertentu. Terkait dengan teknik budidaya ramah lingkungan, pemilihan varietas padi seharusnya juga mempertimbangkan kemampuannya dalam melepaskan metana ke atmosfer yang tergantung pada karakteristik varietas dan kondisi tanah [8]. Perbedaan karakteristik varietas menyebabkan keragaman di antara varietas dalam mengoksidasi dan melepaskan metana ke atmosfer[9].

Pelepasan GRK dari tanah sawah dipengaruhi oleh sifat fisiologi dan morfologi tanaman padi dan eksudat akar yang merupakan 
sumber karbon dan energi bagi aktivitas mikroorganisme yang hidup di rhizosfer termasuk bakteri metanogen [1, 10]. Keragaman emisi $\mathrm{CH}_{4}$ antar kultivar padi ditentukan oleh keragaman ketersediaan eksudat akar dan pembusukan jaringan akar dan daun-daun yang jatuh di dalam tanah, dan keragaman kapasitas pengangkutan $\mathrm{CH}_{4}$ antar varietas padi [2]. Eksudat akar dipengaruhi oleh faktor genetik dan lingkungan termasuk spesies tanaman atau varietas, umur tanaman, suhu, radiasi, unsur hara, lengas tanah, kerusakan akar, dan aplikasi bahan agrokimia melalui permukaan daun[10]. Tujuan dari penelitain ini adalah untuk mengetahui besarnya emisi metana dari beberapa varietas padi unggul tipe baru yang dibudidayakan di lahan sawah tadah hujan.

\section{METODOLOGI}

Percobaan dilaksanakan di lahan sawah tadah hujan di Jakenan, Pati, Jawa Tengah pada musim penghujan 2013. Lokasi percobaan terletak pada ketinggian $15 \mathrm{~m}$ di atas permukaan laut dengan koordinat $111^{\circ} 10^{\prime}$ BT dan $6^{\circ} 45^{\prime}$ LS. Tanah di lokasi percobaan adalah Inceptisol yang mengandung C organik rendah $(<2 \%), \mathrm{N}$ total rendah, $\mathrm{P}$ total rendah, kapasitas tukar kation rendah $\left[<16 \mathrm{cmol}(+) \mathrm{kg}^{-1}\right]$ dan kation dapat ditukar rendah (Tabel 1). Kondisi kandungan hara rendah mencerminkan bahwa status kesuburan kimiawi tanah sawah tadah hujan termasuk kategori rendah.

Percobaan disusun mengunakan rancangan acak kelompok diulang tiga kali dengan perlakuan varietas padi meliputi Inpari 14, Inpari 15, Inpari 17, Inpari 18, Inpari 20, Situ Bagendit, dan varietas kontrol (IR64 dan Ciherang).

Varietas padi ditanam dengan sistem tanam pindah pada tanggal 5 Januari 2013. Tanah diolah dengan bajak, diratakan, dan dibuat petakan-petakan dengan ukuran $6 \mathrm{~m}$ X 10 m. Bibit varietas padi ditanam pindah dari persemaian setelah umur 15 hari dengan jarak tanam $20 \mathrm{~cm}$ X $20 \mathrm{~cm}$ masing-masing satu bibit per lubang. Panen padi dilakukan tanggal 16 April 2013.

Masing-masing petakan diberi pupuk N P K dengan takaran $120 \mathrm{~kg} \mathrm{~N}, 36 \mathrm{~kg} \mathrm{P}_{2} \mathrm{O}_{5}$, dan $60 \mathrm{~kg} \mathrm{~K} \mathrm{O}_{2}$ setiap hektarnya. Pupuk N dalam bentuk urea diberikan tiga tahap, masingmasing $1 / 3 \mathrm{~N}$ ketika 7,40 , dan 55 hari setelah tanam pindah. Pupuk P diberikan sekaligus dan pupuk K diberikan secara dua tahap yaitu $1 / 2 \mathrm{~K}$ pada $7 \mathrm{hst}$ dan $1 / 2 \mathrm{~K}$ saat $40 \mathrm{hst}$.

Tabel 1. Karakteristik tanah sawah Inceptisol di KP Jakenan Pati, Jawa Tengah, 2013

\begin{tabular}{|c|c|}
\hline Karakteristik tanah & Harkat $^{1)}$ \\
\hline C organik (\%) & $1,89 \pm 0,16$ \\
\hline $\mathrm{N}$ total $(\%)$ & $0,17 \pm 0,04$ \\
\hline$P$ total $(\%)$ & $0,04 \pm 0,03$ \\
\hline $\mathrm{K}$ total $(\%)$ & $5,05 \pm 1,59$ \\
\hline K T K [cmol (+) kg-1] & $4,24 \pm 1,40$ \\
\hline \multicolumn{2}{|l|}{ Kation dapat ditukar : } \\
\hline $\mathrm{K} \quad\left[\mathrm{cmol}(+) \mathrm{kg}^{-1}\right]$ & $0,02 \pm 0,01$ \\
\hline $\mathrm{Na}\left[\mathrm{cmol}(+) \mathrm{kg}^{-1}\right]$ & $1,19 \pm 0,67$ \\
\hline $\mathrm{Ca}\left[\mathrm{cmol}(+) \mathrm{kg}^{-1}\right]$ & $7,12 \pm 2,75$ \\
\hline $\operatorname{Mg}\left[\mathrm{cmol}(+) \mathrm{kg}^{-1}\right]$ & $1,51 \pm 0,74$ \\
\hline
\end{tabular}


Data yang diamati meliputi emisi metana $\left(\mathrm{CH}_{4}\right)$ yang dihitung dari fluks $\mathrm{CH}_{4}$ pada fase pertumbuhan anakan aktif, anakan maksimum, primordia bunga, dan pengisian bulir padi; hasil gabah dan biomassa padi dari ubinan $3 \mathrm{~m}$ X $5 \mathrm{~m}$. Contoh gas diambil dengan menggunakan sungkup tertutup pada interval waktu 5, 10, 15, 20 menit. Sungkup yang digunakan berukuran $40 \mathrm{~cm} \mathrm{X} 40 \mathrm{~cm} \mathrm{X} 100$ $\mathrm{cm}$. Contoh gas diambil menggunakan syringe volume $10 \mathrm{ml}$. Contoh gas diinjeksikan ke alat kromatografi gas yang dilengkapi dengan detektor FID untuk penetapan fluk $\mathrm{CH}_{4}$. Penetapan fluk $\mathrm{CH}_{4}$ menggunakan formula dari International Atomic Energy Agency IAEA tahun 1995[12]. Data yang terkumpul dianalisis menggunakan sidik ragam dan dilanjutkan dengan uji DMRT taraf 5\%.

\section{HASIL DAN PEMBAHASAN}

\section{Emisi Metana}

Varietas padi yang dibudidayakan di ekosistem sawah tadah hujan menentukan besarnya emisi metana $(p<0,0001)$. Perbedaan emisi antar varietas dipengaruhi oleh keragaman sifat morfologi dan fisiologi tanaman, serta eksudasi di perakaran tanaman. Pelepasan metana dari varietas padi Inpari 17 dan Inpari 18 adalah lebih rendah daripada Inpari 14, 15, dan 20. Inpari 15 mengemisi metana tertinggi diikuti Inpari 14 dan Inpari 20 yang lebih tinggi daripada varietas Situ Bagendit, Ciherang, dan IR64 (Tabel 2). Selama pertumbuhan tanaman, kondisi lahan tergenang dengan ketinggian air dipermukaan sawah lebih daripada 4 cm kecuali pada fase pemasakan dengan tinggi air sawah $2 \mathrm{~cm}$. Kondisi reduktif tersebut menguntungkan terjadi pembentukan metana yang berlangsung dengan baik seperti ditunjukkan oleh redoks potensial lebih rendah daripada -100 mV (Gambar 1). Produksi $\mathrm{CH}_{4}$ meningkat secara eksponensial dengan penurunan Eh tanah dengan kisaran -150 hingga $-200 \mathrm{mV}$ [13]. Pada nilai kisaran Eh tersebut, aktivitas mikroba methanogen dalam kondisi optimum, apalagi didukung oleh suhu tanah dalam kisaran $30-40{ }^{\circ} \mathrm{C}$.

Angka dalam lajur sama diikuti huruf sama berarti tidak berbeda nyata pada taraf 0,05 menurut uji beda nyata terkecil

Varietas Situ Bagendit potensial mengemisi metana rendah meskipun emisinya relatif lebih tinggi dibandingkan Ciherang dan IR64. Situ Bagendit adalah varietas padi gogo yang mampu tumbuh baik di lahan sawah tadah hujan, sehingga konversi media tanam dari sisem padi sawah ke sistem padi aerobic (gogo

Tabel 2. Emisi metana dari varietas padi unggul tipe baru di sawah tadah hujan, MH 2013

\begin{tabular}{lcc}
\hline Varietas padi & $\begin{array}{c}\text { Emisi metana } \\
\left(\mathrm{kg} \mathrm{CH}_{4} \mathrm{ha}^{-1} \mathrm{musim}^{-1}\right)\end{array}$ & $\begin{array}{c}\text { Nisbah metana/gabah } \\
\left(\mathrm{kg} \mathrm{CH}_{4} \mathrm{~kg}^{-1} \text { gabah }\right)\end{array}$ \\
\hline Inpari 14 & $295 \mathrm{~b}$ & $0,0052 \mathrm{a}$ \\
Inpari 15 & $310 \mathrm{a}$ & $0,042 \mathrm{~b}$ \\
Inpari 17 & $86 \mathrm{~g}$ & $0,010 \mathrm{~g}$ \\
Inpari 18 & $82 \mathrm{~g}$ & $0,010 \mathrm{~g}$ \\
Inpari 20 & $180 \mathrm{C}$ & $0,026 \mathrm{~d}$ \\
Situ Bagendit & $123 \mathrm{e}$ & $0,016 \mathrm{f}$ \\
Ciherang & $150 \mathrm{~d}$ & $0,030 \mathrm{c}$ \\
IR64 & $108 \mathrm{f}$ & $0,020 \mathrm{e}$ \\
\hline Koefisien keragaman (\%) & 2,85 & 3,18 \\
\hline
\end{tabular}




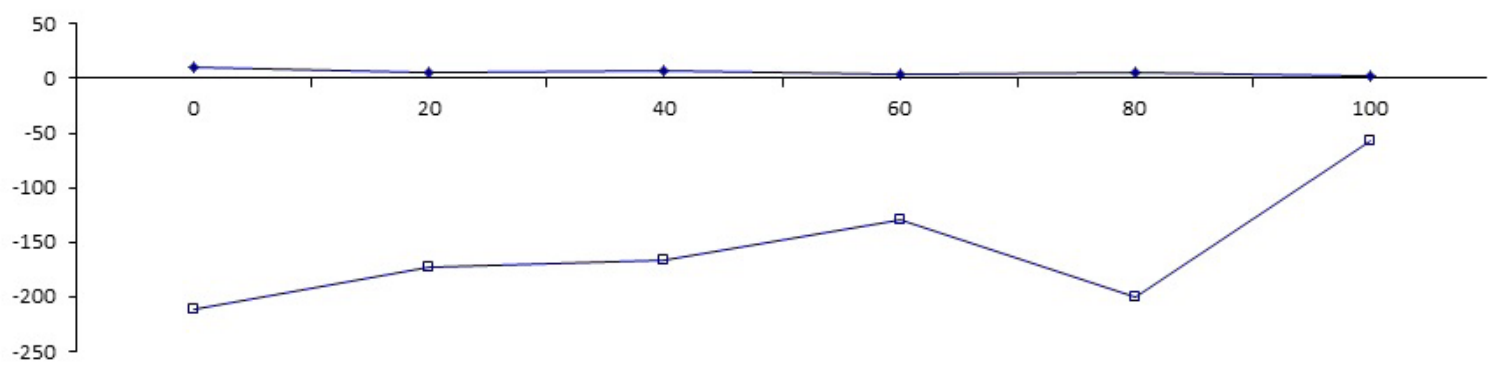

Hari setelah tanam (hst)

Gambar 1. Tinggi air sawah dan potensial redoks pada beberapa fase pertumbuhan tanaman padi

atau gogorancah) akan menurunkan emisi metana[14]. Keragaman sifat morfologi dan fisiologi antar varietas menentukan besarnya metana yang dilepaskan ke atmosfer. Sekitar 70\% metana dilepaskan ke atmosfer melalui jaringan aerenkhima tanaman padi. Awal pertumbuhan, metana terperangkap tanah dilepaskan ke atmosfer melalui ebulisi yang disebabkan oleh praktek budidaya seperti olah tanah, pelumpuran, perataan tanah, tanam, pemupukan, dan penyiangan. Selama fase pertumbuhan reproduktif, lebih dari $90 \%$ emisi berasal dari tanaman padi $[1,2]$. Laju emisi metana meningkat mulai dari fase vegetative hingga fase reproduktif dan puncaknya terjadi pada periode pemasakan dari padi sawah di ekosistem irigasi [3].

Tiap-tiap varietas padi mempunyai sifat dan aktivitas akar berbeda, seperti eksudat akar dan laju perubahan gas yang berkaitan dengan volume emisi $\mathrm{CH}_{4}$ [15]. Varietas Inpari 17, Inpari 18, dan IR64 diduga menghasilkan eksudat akar lebih rendah daripada Inpari 14 dan Inpari 15. Bakteri metanogen menggunakan eksudat akar dan massa akar tanaman padi sebagai sumber karbon dalam menghasilkan $\mathrm{CH}_{4}$ [16]. Produksi eksudat akar tanaman padi lebih aktif terjadi saat fase pertumbuhan reproduktif terutama pada saat keluarnya daun bendera. Pada fase pertumbuhan tersebut, kondisi lingkungan menguntungkan karena ketersediaan air hujan mencukupi bagi pertumbuhan tanaman yang lebih baik [9] Eksudat akar dibutuhkan bakteri metanogen dalam metabolismenya untuk membentuk gas metana. Eksudat akar merupakan bahan organik seperti karbohidrat yang merupakan penyusun utama, asam-asam organik, asamasam amino yang difermentasikan menjadi asetat atau $\mathrm{CO}_{2}$ dan $\mathrm{H}^{+}$, yang akan diubah menjadi metana oleh bakteri metanogen [6].

Besarnya fluks metana antar varietas padi dipengaruhi oleh bobot biomassa tanaman. Besarnya biomassa akar dapat meningkatkan produksi metana, dimana biomassa akar mempunyai korelasi positif dengan produksi metana $[5,8]$. Tingginya biomassa akar tanaman padi meningkatkan jumlah karbohidrat dari perakaran, eksudat akar, dan akar yang membusuk merupakan sumber karbon yang penting untuk produksi metana di lahan sawah sesuai dengan perkembangan tanaman. Eksudasi senyawa karbon pada kondisi tanah reduktif tersebut dapat digunakan baik secara 
langsung maupun tidak langsung oleh bakteri metanogen dalam menghasilkan gas metana [13].

Nisbah antara emisi metana dan hasil gabah sebagai indeks emisi untuk memprediksi varietas padi yang potensial menghasilkan gabah tertinggi dan memberikan kontribusi emisi metana terendah[17]. Tabel 2 memperlihatkan keragaman nyata nisbah metana dan hasil gabah antar varietas yang diuji $(\mathrm{p}<0,0001)$. Nilai nisbah metana dan hasil gabah makin rendah berarti daya hasil varietas yang diuji makin tinggi dan emisi metana makin rendah. Nisbah metana dan hasil gabah dari varietas Inpari 17 dan Inpari 18 adalah terendah $\left(0,01 \mathrm{~kg} \mathrm{CH}_{4} \mathrm{~kg}^{-1}\right.$ gabah) diikuti varietas Situ Bagendit $\left(0,016 \mathrm{~kg} \mathrm{CH}_{4}\right.$ $\mathrm{kg}^{-1}$ gabah) dan varietas IR64 $\left(0,02 \mathrm{~kg} \mathrm{CH}_{4}\right.$ $\mathrm{kg}^{-1}$ gabah), sedangkan nilai nisbah tertinggi ditunjukkan oleh varietas Inpari 14 yang diikuti Inpari 15 (Tabel 2).

\section{Hasil Gabah dan Biomassa}

Varietas padi sawah yang dibudidayakan di ekosistem sawah tadah hujan nyata menghasilkan gabah dan biomassa yang beragam $(\mathrm{P}<0,0001)$. Hasil gabah dari varietas padi yang diuji secara berurutan: Inpari $17<$ Inpari $18<$ Situ Bagendit < Inpari $15<$ Inpari $20<$ Inpari $14<$ IR64 < Ciherang (Tabel 3). Varietas padi unggul tipe baru Inpari umumnya menghasilkan gabah lebih tinggi daripada varietas padi unggul yang lama seperti IR64 dan Ciherang. Tingginya hasil gabah varietas Inpari 17 dan 18 ditentukan pula oleh tingginya indeks panen yang masing-masing nilainya 0,74 dan 0,77 (Tabel 3). Indeks panen dari varietas IR64 dan Ciherang masing-masing adalah 0,46 dan 0,43 . Tingginya hasil gabah varietas padi tersebut dipengaruhi oleh jumlah daun dari anakan yang aktif berfotosintesis terutama pada fase pengisian bulir[18]. Laju fotosintesis tinggi meningkatkan produktivitas tanaman yang tergantung pada indeks luas daun, bentuk kanopi, dan produktivitas biomassa kering dari masing-masing varietas yang diuji. Varietas unggul tipe baru yang diuji umumnya mempunyai batang kuat, daun tegak, dan berwarna hijau tua dengan system perakaran baik sehingga mampu berkembang di tanah sawah tadah hujan dan menghasilkan gabah nyata.

Varietas padi nyata menghasilkan biomassa yang beragam. Bobot biomassa saat panen

Tabel 3. Hasil gabah dan bobot biomassa dari varietas inbrida padi di sawah tadah hujan, MH 2013

\begin{tabular}{lccc}
\hline \multirow{2}{*}{ Varietas padi } & \multicolumn{2}{c}{ Hasil padi $\left(\mathrm{kg} \mathrm{ha}^{-1}\right)$} & \multirow{2}{*}{ Indeks panen } \\
\cline { 2 - 3 } & \multicolumn{1}{c}{ Gabah kadar air 14\% } & Biomassa kering & \\
\hline Inpari 14 & $5,652 \mathrm{e}$ & $11,077 \mathrm{de}$ & $0,51 \mathrm{~d}$ \\
Inpari 15 & $7,361 \mathrm{c}$ & $12,601 \mathrm{a}$ & $0,58 \mathrm{c}$ \\
Inpari 17 & $8,487 \mathrm{a}$ & $11,382 \mathrm{~cd}$ & $0,74 \mathrm{a}$ \\
Inpari 18 & $7,923 \mathrm{~b}$ & $10,264 \mathrm{f}$ & $0,77 \mathrm{a}$ \\
Inpari 20 & $6,917 \mathrm{~d}$ & $10,670 \mathrm{ef}$ & $0,64 \mathrm{~b}$ \\
Situ Bagendit & $7,733 \mathrm{~b}$ & $12,296 \mathrm{ab}$ & $0,63 \mathrm{bc}$ \\
Ciherang & $5,001 \mathrm{f}$ & $11,687 \mathrm{bcd}$ & $0,43 \mathrm{e}$ \\
IR64 & $5,402 \mathrm{e}$ & $11,788 \mathrm{bc}$ & $0,46 \mathrm{de}$ \\
\hline Koefisien keragaman (\%) & 2,05 & 2,49 & 3,79 \\
\hline
\end{tabular}

Angka dalam lajur sama diikuti huruf sama berarti tidak berbeda nyata pada taraf 0,05 menurut uji beda nyata terkecil 
tertinggi dihasilkan oleh varietas Inpari 15 diikuti Situ bagendit. Bobot biomassa terendah dihasilkan oleh Inpari 18 dan Inpari 20 (Tabel 3). Varietas Situ bagendit tampak mampu menyesuaikan dengan sistem sawah tadah hujan.

\section{SIMPULAN}

Varietas padi unggul tipe baru Inpari 17 dan Inpari 18 yang dibudidayakan di ekosistem sawah tadah hujan menghasilkan gabah dan indeks panen tertinggi. Inpari 17 dan 18 merupakan kultivar padi dengan potensi hasil tinggi dan tingkat emisi metana paling rendah daripada varietas inbrida lain yang diuji. Nisbah antara emisi metana dan hasil gabah untuk Inpari 17 dan 18 adalah 0,01 $\mathrm{kg} \mathrm{CH} \mathrm{kg}^{-1}$ gabah. Varietas padi Inpari 14 dan 15 menghasilkan metana lebih tinggi dibandingkaan varietas Ciherang, IR64, dan Situ Bagendit

\section{UCAPAN TERIMA KASIH}

Penulis mengucapkan terima kasih kepada Wasidin, Jumari, dan Suyoto yang telah membantu dalam pengambilan contoh gas di lapangan, dan kepada Titi Soepiawati atas bantuannya dalam analisis fluks metana di laboratorium GRK Balai Penelitian Lingkungan Pertanian.

\section{DAFTAR PUSTAKA}

(1) Neue, H.U. 1993. Methane emission from rice fields : Wetland rice fields may make a major contribution toglobal warming. Bioscience 43(7): 466-473.
(2) Dubey, S.K. 2005. Microbial ecology of methane emission in rice agroecosystems : A review. Applied Ecology and Environmental Research 3(2): 1-27.

(3) Wassmann, R., G.C. Nelson, S.B. Peng, K. Sumfleth, S.V.K. Jagadish, Y. Hosen, \& M.W. Rosegrant. 2010. Rice and global climate change. In: Pandey et al. editors. Rice in The Global Economy: Strategic Research and Policy Issues for Good Security. International Rice Research Institute. Los Banos, Philippines. p. 411-432.

(4) van Zwielen, L., B. Singh, S. Joseph, S. Kimber, A. Cowie, \& K.Y. Chan. 2009. Biochar and emissions on non$\mathrm{CO}_{2}$ greenhouse gases from soil. $\mathrm{p}$. 227.

(5) Neue, H.U., \& R.L. Sass. 1994. Trace gas emission from rice fields. Environ. Sci. Research 48: 119 - 147.

(6) Holzapfel-Pschron, A., R. Conrad, \& W. Seiler. 1986. Effect of vegetation on the emission of methane from submerged paddy soil. Plant Soil 92: $223-233$.

(7) Nouchi, I. 1992. Mechanism of methane transport through rice plants. In Proceeding of $\mathrm{CH}_{4}$ and $\mathrm{N}_{2} \mathrm{O}$ Workshop : $\mathrm{CH}_{4}$ and $\mathrm{N}_{2} \mathrm{O}$ emissions from natural and antropogenic sources and their reduction research plant. National Research of AgroEnvironmental Sciences. Tsukuba. Japan.

(8) Neue, H.U., \& P.A. Roger. 1993. Rice Agriculture : Factors controlling emission. Pages XXX in M.A.K. Khalil, \& M. Shearer (Eds.). Global Atmospheric Methane. NATO ASI/ ARW Series. 
(9) Wihardjaka, A., \& A.K. Makarim. 2001. Emisi gas metan melalui beberapa varietas padi pada tanah Inceptisol yang disawahkan. Penelitian Pertanian Tanaman Pangan 20(1): 10-16.

(10) Murphy, J.A., S.L. Murphy, \& H. Samaranayake. 2006. Soil physical cobstraints and plant growth interaction. p. 387-406 in Wilkinson, R.E. (Ed.). Plant-Environment Interactions. $2^{\text {nd }}$ Edition. Marcel Dekker, Inc. Madison Avenue, New York.

(11) Suprihatno, B., A.A. Daradjat, Satoto, Baehaki, S.E., Suprihanto, A. Setyono, S.D. Indrasari, P. Wardhana, \& H. Sembiring. 2010. Deskripsi Varietas Padi. Balai Besar Penelitian Tanaman Padi. Subang.

(12) Iqbal, J., R. Hu, S. Lin, R. Hatano, M. Feng, L. Lu, B. Ahamadou, \& L. Du. 2009. $\mathrm{CO}_{2}$ emission in a subtropical red paddy soil (Ultisols) as affected by straw and $\mathrm{N}$-fertilizer applications : A case study in Southern China. Agriculture, Ecosystems and Environment 131: 292-302.

(13) Wassman, R., H. Papen, \& H. Rennenberg. 1993. Methane emission from rice paddies and possible mitigation strategies. Chemosphere 26: 201-217.
(14) Wassmann, R., H.U. Neue, J.K. Ladha, \& M.S. Aulakh. 2004. Mitigating greenhouse gas emission from ricewheat cropping systems in Asia. Environment, Development and Sustainability 6: 65-90.

(15) Wagatsuma, T., T. Nakashima, T. Tawaraya, S. Watanabe, A. Kamio, \& A. Ueki. 1990. Role of plant aerenchyma in wet tolerance and methane emission from plants. $p$. 455-461 in M.L. van Beusichem (Ed.). Plant Nutrition, Plant Physiology and Application. Kluwer Acad. Publ.

(16) Shalini-Singh, S. Kumar, \& M.C. Jain. 1997. Methane emission from two Indian soils planted with different rice cultivars. Biol. Fertil. Soils 25: 285-289.

(17) Subadiyasa, Netera, Nyoman Arya, \& Makoto Kimina. 1997. Methane emissions from paddy field in Bali Island, Indonesia. Soil Sci. Plant Nutr. 43: 387-394.

(18) Abdullah, B., S. Tjokrowidjojo, \& Sularjo. 2008. Status, perkembangan, dan prospek pembentukan padi tipe baru di Indonesia. Prosiding Simposium V Tanaman Pangan, Inovasi Teknologi Tanaman Pangan. Buku 2. Pusat Penelitian dan Pengembangan Tanaman Pangan. Bogor. Hlm. 269-287. 